\title{
Role of Phonophoresis in Management of Adhesive Capsulitis (Frozen Shoulder)
}

\author{
Sunam Kumar Barua ${ }^{1 *}$ \\ Sohely Rahman' \\ Proshanta Kumar Chakrabarti ${ }^{1}$ \\ Zahangir Alam ${ }^{2}$
}

'Department of Physical Medicine Dhaka Medical College

Dhaka, Bangladesh.

${ }^{2}$ Department of Physical Medicine Chattagram Maa-O-Shishu Hospital Medical College Chittagong, Bangladesh.

\section{*Correspondence to:}

\section{Dr. Sunam Kumar Barua}

Assistant Professor

Department of Physical Medicine

Dhaka Medical College

Dhaka, Bangladesh.

Mobile : +8801819190812

E-mail: sunam1971@hotmail.com, sunambarua@gmail.com

\begin{abstract}
This prospective study was performed in the department of Physical Medicine, Dhaka Medical College Hospital (DMCH), Dhaka for a period of 6 months to see the effect of phonophoresis (Ultrasound therapy with Naproxen gel) on adhesive capsulitis. During this period 240 (4\% of total patients) patients were diagnosed as adhesive capsulitis of shoulder in outpatient department, Physical Medicine, Dhaka Medical College Hospital. Sixty patients were selected for the study and divided them into two groups. In group A, patients were treated with phonophoresis and exercises in contrast with group B patients who were treated with same exercises without phonophoresis for same duration. Patients in both groups were followed up weekly for consecutive six weeks. The mean age of the patients in this study was $51.73 \pm 10.01$ year, with a range of 35 to 70 years. Out of sixty patients $31(51.7 \%)$ were male and $29(48.3 \%)$ were female. The male: female ratio was 1.07: 1. Among 60 patients, 27 (45\%) were housewives, 20 (33.3\%) service holders (official job), 4 $(6.7 \%)$ businessmen, $1(1.7 \%)$ teacher and $8(13.3 \%)$ retired persons. In this study $53.3 \%$ patients had right shoulder involvement and rest of them (46.7\%) had left sided involvement. Pain was improved just after initiation of treatment and it was completely alleviated in group A patients after $6^{\text {th }}$ week, on the contrary although pain was increased after $1^{\text {st }}$ week of treatment thereafter it was gradually decreased but it was not completely alleviated in group B patients at the end of the study. All sorts of range of motions (abduction, internal rotation on abduction, external rotation on abduction) of affected shoulder were improved more rapidly in group A compared to group B patients. Shoulder pain and disability index (SPADI) were significantly reduced in group A compared to group B patients.
\end{abstract}

Key words: Adhesive capsulitis; Phonophoresis; frozen shoulder.

\section{INTRODUCTION}

Adhesive capsulitis is a condition characterized by limitation of motion of the shoulder joint with pain at the extremes of motion. It was first described by Putaman in1882 and later by Codman. The initial presentation is pain, which is generalized and referred to the upper arm, back, and neck. As pain increases, loss of joint motion ensues. The process is generally self limiting and in most cases resolves spontaneously unless there is an underlying problem ${ }^{1}$. In the early phase, there is marked anterior joint/ capsular tenderness and stress pain in a capsular pattern, later there is painless restriction, often of all movements ${ }^{2}$.

Adhesive capsulitis, also known as frozen shoulder, pericapsulitis, scapulohumeral periarthritis or check- rein syndrome ${ }^{3}$. The condition usually resolves spontaneously after about 18 months ${ }^{4}$.

Adhesive capsulitis is a common musculoskeletal disorder mainly affecting middle aged adults ${ }^{5}$. Self care and occupational activities decreases depends upon which shoulder is involved, for instance, self care, grooming, eating and dressing are impaired if right shoulder is involved for right handed person, on the other hand dressing and perineal care are hampered if left shoulder is involved. 
Adhesive capsulitis should be divided into primary and secondary types. Subdivision of secondary adhesive capsulitis in to intrinsic, extrinsic and systemic types ${ }^{6}$. Primary adhesive capsulitis and idiopathic adhesive capsulitis are considered identical and not associated with a systemic condition or history of injury. Another classification system based on patient's irritability level (low, moderate and high) that is helpful when making clinical decisions regarding rehabilitation intervention? ${ }^{7}$.

A global decrease in shoulder range of motion referring to the actual adherence of the shoulder capsule to the humeral head. Secondary causes include alteration of the supporting structures of and around the shoulder, autoimmune, endocrine or other systemic diseases ${ }^{8}$.

Adhesive capsulitis is more common in diabetes mellitus ${ }^{2,9,10}$, and may be triggered by a rotator cuff tear, local trauma, myocardial infarction or hemiplegia ${ }^{2}$, immobilization from any cause $^{11}$. It occasionally appears after recovery from neurosurgery ${ }^{4}$.

The histological features are reminiscent of Dupuytren's disease, with active fibroblastic proliferation in the rotator interval, anterior capsule and coraco- humeral ligament ${ }^{4}$.

Three stages, each lasting 4-6 months, mark the clinical course. The progression of the disease is self- limiting and may occasionally resolve in partial restitution ${ }^{12}$. Stage one is the painful or freezing phase. During this stage, the pain is severe, is exacerbated by any attempts at movement, and lasts a few weeks or months. Phase two is the adhesive or stiffening phase and generally lasts 4 to 12 months. Pain is usually minimal during this phase, although periarticular symptoms may be developed from compensatory motion to achieve elevation of the arm. The third phase of the syndrome is the resolution or thawing phase and may last 5 to 26 months. During this time the pain eases, and motion slowly improves, although some patients may improve dramatically over a short period ${ }^{1}$.

The loss of range is multi planar, with external rotation and abduction being the most affected. Restricted passive external rotation as diagnostic of frozen shoulder would standardize and may clarify the clinical aspect of diagnosis ${ }^{13}$. Clinically the diagnosis should be suspected with progressive loss of range and diffuse pain despite conservative treatment measures ${ }^{9}$. Apart from slight wasting, the shoulder looks quite normal, tenderness is seldom marked. The shoulder is tender on palpation and both active and passive movements in all directions are restricted ${ }^{9}$. One clinical test alone is generally not sufficient to make a pathoanatomical diagnosis ${ }^{14}$.

Idiopathic adhesive capsulitis is a common medical diagnosis for patients seeking physical therapy. Modalities used to treat adhesive capsulitis were dichotomized by pain predominant and stiffness-predominant classifications, which may be more useful than existing classifications ${ }^{13}$. Several treatment options are commonly used, but few have high level evidence to support them ${ }^{15}$. Physical therapy play an important role in the treatment of many shoulder pain including adhesive capsulitis ${ }^{16}$.
Clinical studies do not show clear effects of specific treatment. This may be caused by methodological weaknesses of the trials evaluated and that patient characteristics and placebo effects contribute to the diagnosis ${ }^{14}$.

The transmission of drugs through the intact skin using ultrasound is called phonophoresis. Griffin and coworkers recommended phonophoresis treatment in common musculoskeletal diseases including adhesive capsulitis of shoulder ${ }^{17}$.

Phonophoresis is a variant of ultrasound in which biologically active substances are combined with the coupling medium in the hope that ultrasound will force the active material into tissue $^{18}$. For instance, NSAIDs gel is used in combination with coupling medium to enhance pain relief for local action. Although this technique has been in use since the 1960s, neither its effectiveness, penetration, optimal frequency, appropriate coupling mediums/ active materials, nor amount of material lost to the subcutaneous circulation is well established. Although some clinical studies report phonophoresis with a variety of agents successful in terms of improved shoulder range of motion and pain following treatment ${ }^{18}$. Perhaps mechanism of transdermal migration could involve increased cell permeability from the thermal effects of ultrasound. Ultrasonic coupling gel is mixed with various chemical substances to produce the phonophoresis coupling agent. Typical phonophoresis treatment parameters are similar to those of standard ultrasound: pulsed mode, $1 \mathrm{MHz}$ transducer frequency, stroking technique, at $1-1.5 \mathrm{~W} / \mathrm{cm}^{2}$, for approximately 5 to $10 \mathrm{~min}$ per site ${ }^{19}$.

\section{MATERIALS \& METHODS}

This was a prospective study conducted on adhesive capsulitis patients in the department of Physical Medicine \& Rehabilitation, Dhaka Medical College Hospital from February 1, 2011 to July 31, 2011 (six months). Within that period approximately 6000 patients were registered in the outdoor of Physical Medicine and Rehabilitation department, Dhaka Medical College Hospital. Among them 240 were diagnosed as adhesive capsulitis from history, physical examination and relevant investigations to exclude other causes. Sixty patients were randomly selected who were fulfilling the selection criteria (inclusion and exclusion criteria). Sixty patients were selected (Thirty of them were in group A and rest were in group B) based on inclusion and exclusion criteria. Inclusion criteria include age of patient (30-70 yr), both sexes, painful restricted shoulder for 1 to 3 months and involvement of one shoulder. If there was any fracture or dislocation of shoulder joint, neck pain or cervical radiculopathy, any associated diseases like diabetes, malignancy or rheumatic diseases, skin diseases around the affected shoulder or history of stroke or other neurological deficits were excluded from the study. Samples were selected by simple random sampling by lottery.

A detailed history was taken from each of the patient to obtain maximum possible information and a preformed questionnaire was filled up for every patient by the investigator in which age, 
sex, duration of symptoms in months, site of shoulder involved, occupation, family, personal and past history were included. A complete physical examination including general physical examination, examination of shoulder joints and neck was done by the investigator. Movements of the affected shoulder joint were measured by using goniometer.

Routine blood for $\mathrm{CBC}$, routine urine examination, random blood sugar, C- reactive protein, serum uric acid, peripheral blood film to exclude other medical conditions including multiple myeloma etc, X- ray of affected shoulder joint both views to assess any pathology and also to exclude supraspinatus calcification, $\mathrm{X}$ - ray of cervical spine both views and oblique views to exclude cervical spondylosis with radiculopathy if suspected.

For therapeutic trial, patients were divided into two groups. Group A (Phonophoresis with exercise) and Group B (Exercise only).

All patients (sixty ) in both groups were given home shoulder mobilizing exercises - Codman/ pendulum, wall climbing, pulley and wand exercise 5 repetitions each type 3 times daily for consecutive 6 weeks which was demonstrated on $1^{\text {st }}$ day of enrollment in the study. In addition, Group A patients were treated with phonophoresis (UST with Anaflex gel) over the affected shoulder for 10 minutes daily for consecutive 10 days except holidays.

The following parameters were studied in all patients of each group:

i) Measurement of pain by visual analogue scale ${ }^{20}$.

ii) Measurement of tenderness by tenderness grading ${ }^{21}$.

iii) Measurement of range of motion (ROM) of the affected shoulder by goniometer ${ }^{20}$.

a) Abduction

b) Internal Rotation in abduction

c) External Rotation in abduction

iv) Shoulder pain and disability index (SPADI) were recorded by asking face to face questions, followed by calculation of points by using calculator ${ }^{22}$.

All patients in both treatment groups were followed up and assessed by weekly interval for consecutive six weeks using above mentioned parameters. All parameters were measured before and after therapy at every week interval and recorded each time in the datasheet.

The results obtained were subjected to standard statistical procedure. Statistical analysis results were obtained by using window based computer software devised with statistical software SPSS (11.5 version). The results were presented in tables, figures and diagrams. Statistical tests for significance of difference were done using paired $t$ test, independent $t$ test, chi square test and regression. Confounding effects of variables on result were sorted out by linear regression. A " $p$ " value $<0.05$ was considered as significant with $95 \%$ confidence interval.

\section{OBSERVATION \& RESULTS}

Table 1: Group specific age distribution of patients $(n=60)$

\begin{tabular}{cccc} 
Age group in years & Group A & Group B & Total \\
$31-40$ & $3(10 \%)$ & $8(26.7 \%)$ & $11(18.3 \%)$ \\
$41-50$ & $10(33.3 \%)$ & $14(46.7 \%)$ & $24(40 \%)$ \\
$51-60$ & $7(23.3 \%)$ & $6(20 \%)$ & $13(21.7 \%)$ \\
$61-70$ & $10(33.3 \%)$ & $2(6.7 \%)$ & $12(20 \%)$ \\
Total & $30(100 \%)$ & $30(100 \%)$ & $60(100 \%)$ \\
\hline
\end{tabular}

$\mathrm{n}=$ Total number of patients

In group $\mathrm{A}$, mean age of patients was $55.60 \pm 10.29$ years and in group B, $47.87 \pm 8.18$ years. Out of 60 patients, in group A maximum patients $(33.3 \%)$ were in both age groups between 41- 50 years and 61- 70 years, in group B maximum patients were in $41-50$ years age group (46.7\%).

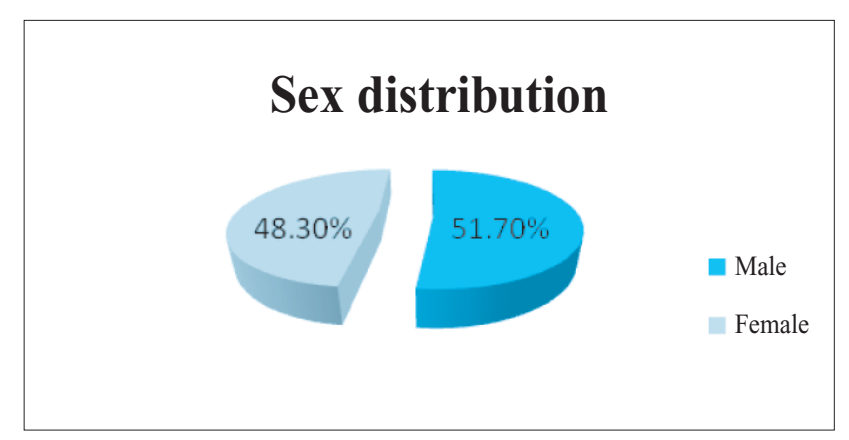

Figure 1: Sex distribution of patients $(n=60)$

In this study male patients were more than female. Among 60 patients, 31 of them were male and 29 were female. The ratio of male and female was 1.07: 1 .

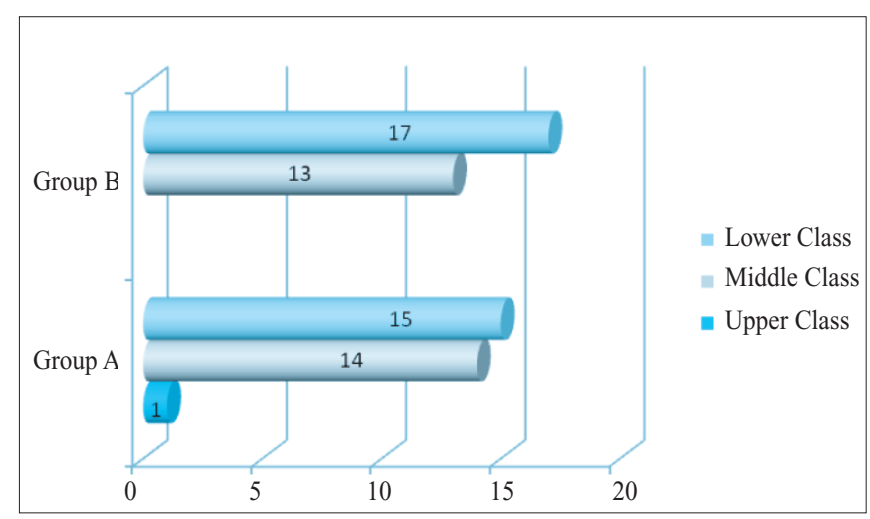

Figure 2: Distribution of patient's socioeconomic condition $(n=60)$

$\mathrm{n}=$ Total number of patients

Most of the patients in both groups (15 patients in group A and 17 patients in group B) were from lower class family. 


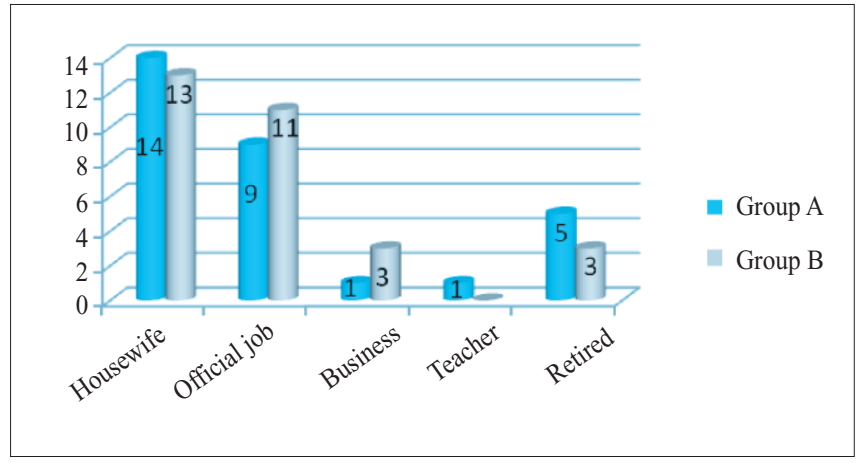

Figure 3: Distribution of group specific occupation of patients

In both groups housewives were more in number, $46.7 \%$ in group A and $43.3 \%$ in group B. $30 \%$ patients in group A and $36.7 \%$ patients in group B were doing official jobs. $16.7 \%$ patients were retired in group A and $10 \%$ in group B. $10 \%$ patients in group B were businessman and only one patient in group A was a teacher.

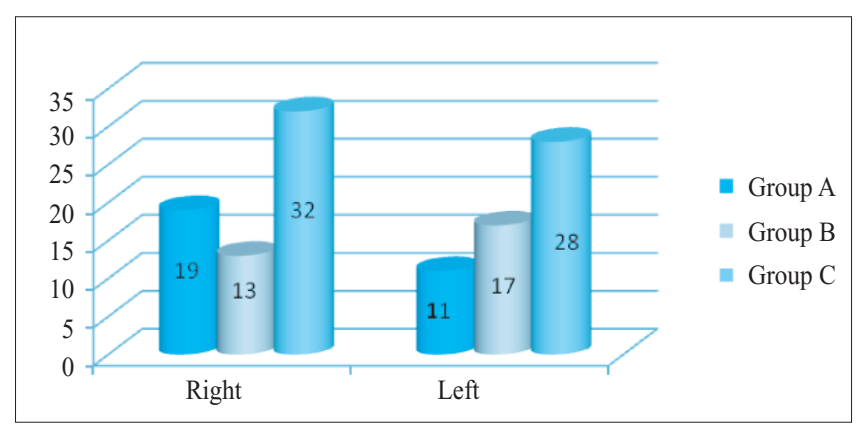

Figure 4: Distribution of group specific site of involvement (Right/ Left shoulder)

Among 30 patients, $19(63.3 \%)$ of them had right sided involvement and $11(36.7 \%)$ had left sided involvement in group $\mathrm{A}$. In group $\mathrm{B}$, right sided involvement was less than left sided involvement (13 and 17 respectively). Although in this study right sided shoulder involvement was found more (53.3\%) than left side.

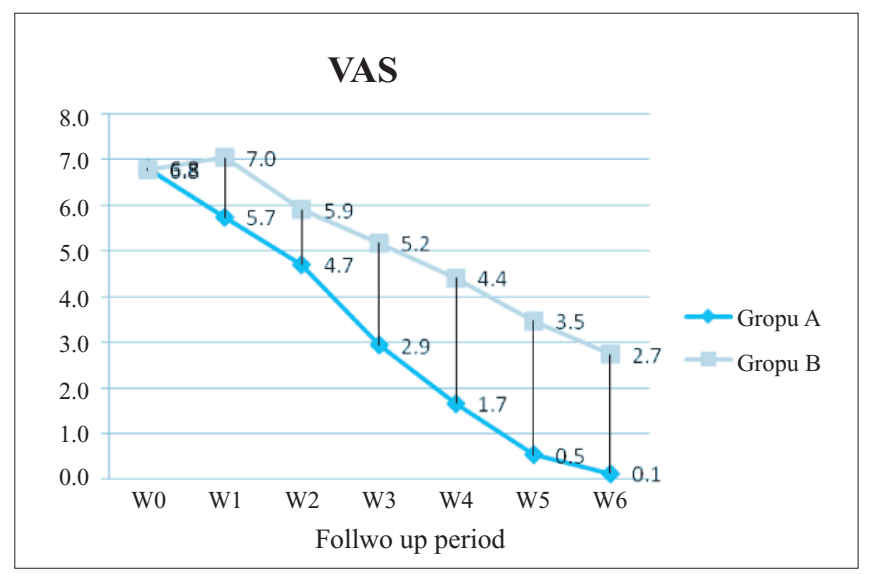

Figure 5: Diagrammatic comparison of improvement of pain (VAS) between Group A and Group B at different time points

Regarding pain, in comparison between two groups, it was found significant difference after one week of treatment $(\mathrm{p}<$ 0.05 ). In every follow up weeks including at the end of $6^{\text {th }}$ week it was remained significant $(\mathrm{p}<0.05)$. This revealed that phonophoresis with exercise is better than exercise without phonophoresis for reducing pain.

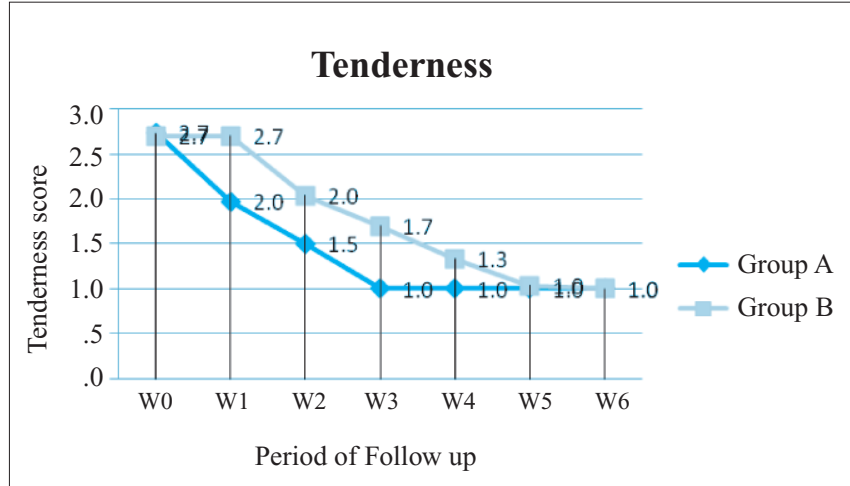

Figure 6: Diagrammatic comparison of improvement of tenderness between Group A and Group B at different time points.

Regarding tenderness, in comparison between two groups, there was found significant difference in reduction of tenderness $(\mathrm{p}<$ 0.05 ) and it was remained up to $4^{\text {th }}$ week. This revealed that phonophoresis has an additional impact to reduce tenderness earlier.

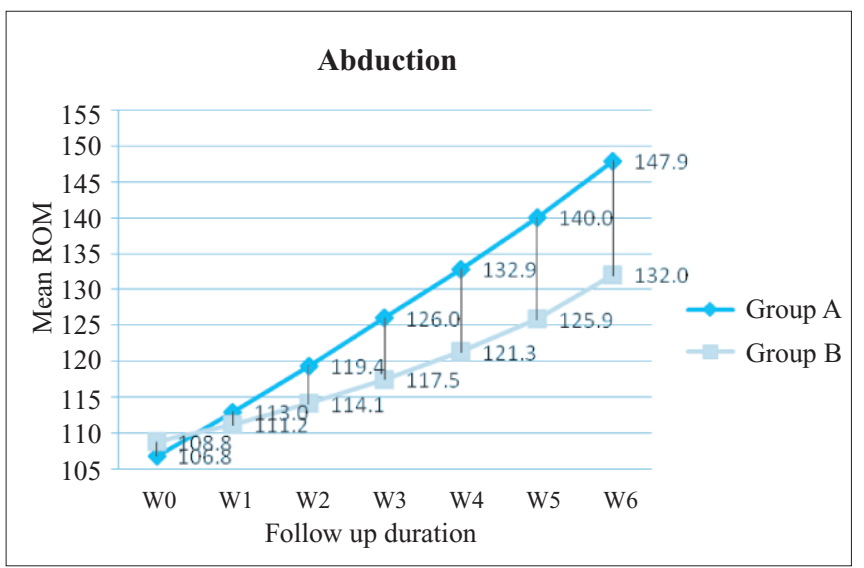

Figure 7: Diagrammatic comparison of improvement of ROM (Abduction) between Group A and Group B at different time points

Regarding ROM (Abduction), there was found significant difference in improvement of ROM (Abduction) between two groups after $3^{\text {rd }}$ week of treatment $(\mathrm{p}<0.05)$ and that was remained up to the end. Phonophoresis with exercise showed better improvement of ROM (abduction) than exercise only.

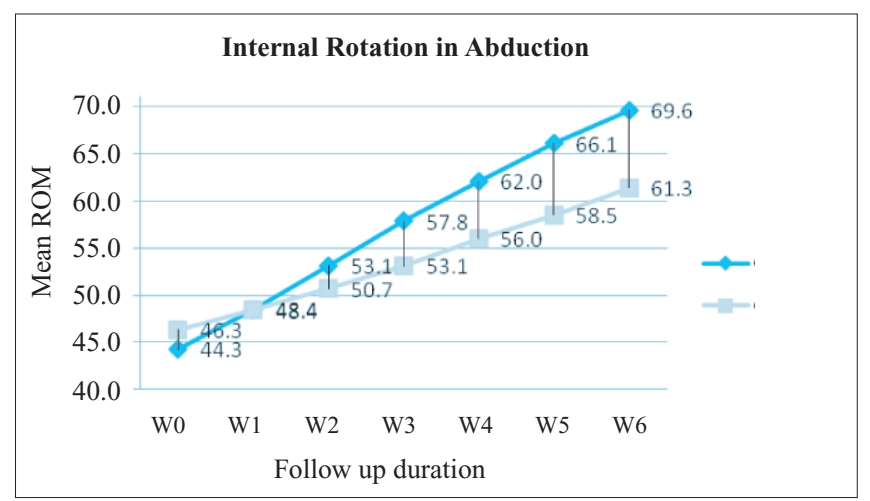

Figure 8: Diagrammatic comparison of improvement of ROM (Internal Rotation) between Group A and Group B at different time points

Regarding ROM (Internal Rotation), in comparison between two groups, there was found significant difference in improvement of ROM (Internal Rotation) after $2^{\text {nd }}$ week of treatment and that was remained up to the end $(\mathrm{p}<0.05)$. Phonophoresis with exercise showed more improvement of ROM (Internal Rotation) than exercise alone. 


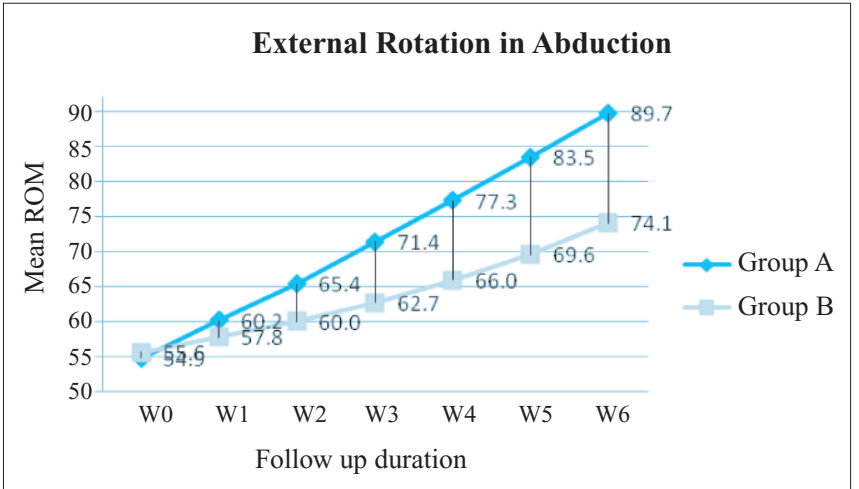

Figure 9: Diagrammatic comparison of improvement of ROM (External Rotation) between Group A and Group B at different time points

Regarding ROM (External Rotation), in comparison between two groups, there was found significant difference in improvement of ROM (External Rotation) after $2^{\text {nd }}$ week of treatment and was remained till the end $(p<0.05)$. Phonophoresis with exercise showed better improvement of ROM (External Rotation) than exercise only.

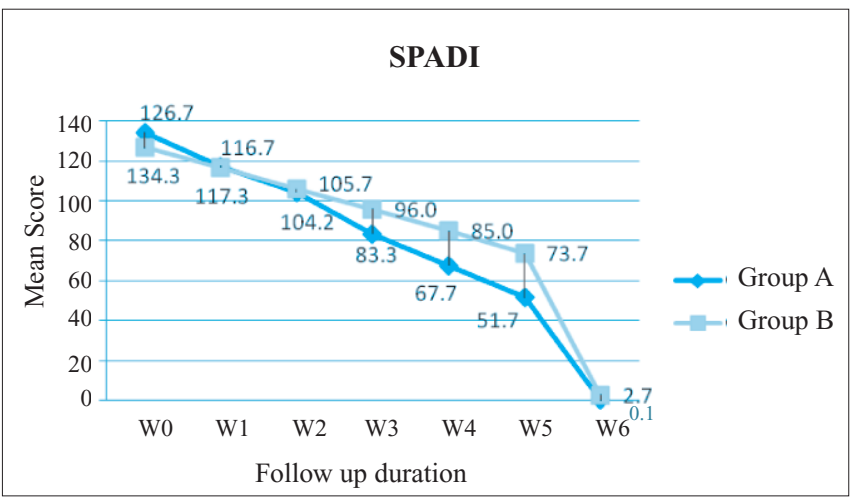

Figure 10: Diagrammatic comparison of improvement of SPADI score between Group A and Group B at different time points.

Regarding SPADI, in comparison between two groups, there was found significant difference in improvement of SPADI scores after $3^{\text {rd }}$ week of treatment and that was remained up to the end $(\mathrm{p}<0.05)$. Phonophoresis with exercise showed better improvement of SPADI scores than exercise only.

\section{DISCUSSION}

Apparently no previous data was found regarding incidence of adhesive capsulitis from any institution/ hospital in Bangladesh. In a study by Bhuiyan $\mathrm{Z} \mathrm{H}^{23}$ found $6.67 \%$ painful shoulder in Rajshahi Medical College Hospital, Rajshahi in 2007. In another study Khan $\mathrm{A} \mathrm{A}^{24}$ found the incidence of painful shoulder was $6.34 \%$ in former IPGMR (Now named as BSMMU), Dhaka in 1993. Majority of the patients with shoulder pain were diagnosed as adhesive capsulitis in their studies.

The mean age of the patients in this study was $51.73 \pm 10.01$ years, with a range of 35 to 70 years. In a study done by Rahman M H etal ${ }^{25}$ was found mean age of patient was $56.24 \pm$
8 years that was slightly higher than the current study as he took the patient within 41 to 70 years, on the other hand study conducted by Bhuiyan $\mathrm{Z} \mathrm{H}^{23}$ found mean age was $49.08 \pm 10.27$ years which is lower than the current study because age range in that study was 25- 69 years. In another study Khan $\mathrm{A} \mathrm{A}^{24}$ found mean age of patients was $51.06 \pm 0.71$ years that is almost similar with current study. In studies done by Celik $\mathrm{D}^{26}$, Jurgel $\mathrm{J}^{27}$, Dogru $\mathrm{H} \mathrm{etal}^{28}$ found mean age of patients was 52.1, 50.2 and 55.3 year respectively.

Both male and female patients were included in the study. Out of sixty adhesive capsulitis patients $31(51.7 \%)$ were male and $29(48.3 \%)$ were female. The male: female ratio was 1.07: 1 . In a study was conducted by Khan $\mathrm{AA}^{24}$ male female ratio was $2: 1$ and another study by Rahman $\mathrm{MH}^{25}$ found 1.77:1 where male were more than female on the other hand Bhuiyan $\mathrm{Z} \mathrm{H}^{23}$ study revealed the ratio was $1: 1.4$, Celic $\mathrm{D}^{26}$ found female male ratio was 3.14:1, Lisinski $\mathrm{P}$ etal $^{29}$ found the ratio was $2: 1$, Dogru $\mathrm{H}$ etal $^{28}$ found ratio was $1.33: 1$. The male preponderance of current and former two studies in Bangladesh could be due to general attitude and ignorance of our female patients to attend doctors and hospitals.

In our study, 27 (45\%) were housewives, 20 (33.3\%) were service holder (official job), 4 (6.7\%) were businessman, 1 $(1.7 \%)$ was teacher and $8(13.3 \%)$ were retired person. Bhuiyan $\mathrm{Z} \mathrm{H} \mathrm{H}^{23}$ found $33.33 \%$ were manual worker, $23.3 \%$ were housewives, $8.34 \%$ were businessman and $10 \%$ were retired. Khan $\mathrm{AA}^{24}$ found maximum patients $(31.67 \%)$ were housewives which are more or less in agreement with our study. Rahman $\mathrm{MH}^{25}$ found $32 \%$ were housewives and $52 \%$ were service holder and retired together.

The current study revealed the occurrence of adhesive capsulitis was more common in lower class family (53.3\%) might be due to most patients in Dhaka Medical College Hospital are coming from lower class family.

In this study $53.3 \%$ patients had right sided involvement and rest $(46.7 \%)$ of them had left sided involvement. Rahman MH etal $^{25}$ and Dogru $\mathrm{H}$ etal ${ }^{28}$ found most of the patients in their study were left shoulder involvement.

Maximum patients (56.7\%) in group A had history of pain for 3 months followed by 2 months but $<3$ months $(36.7 \%)$ and in group B that was $46.7 \%$ had history of pain 2 months but $<$ 3 months followed by 3 months $(43.3 \%)$. Therefore this study revealed that early intervention of physical therapy such as exercises would give better outcome and early restoration of movements, as well as additional implementation of phonophoresis alleviates pain earlier and thus resulting more ROM can be restored.

In comparison between two groups there was no significant difference regarding pain was seen before treatment $(\mathrm{P}>0.05)$ but after treatment there was significant difference in between two groups in every follow up weeks $(\mathrm{P}<0.05)$ and group A showed better outcome than group B. Site of involvement and age group variations in between groups might have role to make such a difference $(\mathrm{p}<0.05)$. The effect of ultrasound therapy in pain reduction was also observed by Bhuiyan $\mathrm{Z} \mathrm{H}^{23}$, Khan $\mathrm{AA}^{24}$, Rahman $\mathrm{MH}$ etal ${ }^{25}$, Dogru $\mathrm{H}_{\text {etal }}{ }^{28}$, Hamer J etal ${ }^{30}$ in their studies. Meta analysis done by Green $\mathrm{S}$ etal ${ }^{31}$ found ultrasound is of no additional benefit over and above exercise alone to reduce pain in adhesive capsulitis. 
In comparison between two groups before treatment there was no significant difference regarding tenderness was seen $(p>0.05)$ but after treatment from the $1^{\text {st }}$ week to $4^{\text {th }}$ week there was significant difference was observed $(\mathrm{p}<0.05)$ means phonophoresis and exercise has better effect compared to exercise alone. Age of the patient could be a confounding factor was detected for such a difference in outcome between two groups. The effect of ultrasound therapy to reduce tenderness was also observed by Khan $\mathrm{AA}^{24}$, Rahman $\mathrm{MH}$ etal ${ }^{25}$ in their studies.

In comparison between two groups there was no significant difference before treatment in improvement of ROM (abduction) $(\mathrm{p}>0.05)$ and up to $2^{\text {nd }}$ week of treatment $(\mathrm{p}>0.05)$. Thereafter the difference of outcome between two groups was significant $(\mathrm{p}<0.05)$. ROM (abduction) was increased more in group A compared to group B because early reduction of pain after phonophoresis might enhance to increase ROM. There was no confounding factor was detected for such a difference in outcome between two groups. The effect of ultrasound therapy had better result in improvement of ROM (abduction) also found by Bhuiyan $\mathrm{Z} \mathrm{H}^{23}$, Khan $\mathrm{AA}^{24}$, Rahman $\mathrm{MH}$ etal ${ }^{25}$, Dogru $\mathrm{H}_{\text {etal }}{ }^{28}$ in their studies.

In comparison between two groups there was no significant difference in improvement of ROM (internal rotation) was found before treatment and up to $1^{\text {st }}$ week of treatment $(p>0.05)$ thereafter outcome of two groups revealed significant difference $(p<0.05)$. ROM (internal rotation) was increased more in group A compared to group B because early reduction of pain after phonophoresis may enhance to increase ROM. Difference in site of involvement between two groups might be a factor for such a different outcomes $(p<0.05)$. Ultrasound therapy showed better result in improvement of ROM (internal rotation) found by Bhuiyan $\mathrm{Z} \mathrm{H}^{23}$, Khan $\mathrm{AA}^{24}$, Rahman $\mathrm{MH}$ $\mathrm{etal}^{25}$ in their studies.

In comparison between two groups there was no significant difference in improvement of ROM (external rotation) before treatment and up to $1^{\text {st }}$ week of treatment $(p>0.05)$ thereafter outcome of two groups was revealed significant difference $(p<0.05)$. ROM (external rotation) was increased more in group A compared to group B because early reduction of pain after phonophoresis may enhance to increase ROM. There was no confounding factor was detected for such a difference in outcome between two groups. Ultrasound therapy showed better result in improvement of ROM (external rotation) found by Bhuiyan $\mathrm{Z} \mathrm{H}^{23}$, Khan $\mathrm{AA}^{24}$, Rahman $\mathrm{MH}$ etal ${ }^{25}$ in their studies.

Functional outcome were assessed by SPADI (Shoulder pain and disability index) score. In comparison between two groups there was significant difference found before treatment $(p<0.05)$ but after $1^{\text {st }}$ and $2^{\text {nd }}$ week of treatment there was no significant difference observed $(p>0.05)$ because the improvement of SPADI scores in both groups were similar. Thereafter outcome of SPADI scores between two groups revealed significant difference $(p<0.05)$. SPADI score was reduced more in group A compared to group B because early reduction of pain and increased ROM after phonophoresis. Site of involvement in between two groups might play a role in such a difference $(\mathrm{p}<0.05)$.
Ultrasound therapy showed better outcome of Shoulder pain and disability index (SPADI) score found by Bhuiyan $\mathrm{Z} \mathrm{H}^{23}$, Dogru $\mathrm{H}_{\text {etal }}{ }^{28}$ in their studies.

During phonophoresis, patients came in close contact with the physiotherapist and it became imperative during therapy to talk each other to make the environment homely and thereby patients became well tolerated, well motivated and well convinced to do their home exercises properly for their betterment but it happened comparatively less in exercises only where the patients did exercises mostly at home and had contact with the physiotherapist and doctor only in weekly follow up. Thus this could be a factor for better compliance in group A patients.

Exercise alone also showed significant pain relief, improvement of ROM (abduction, internal rotation in abduction, external rotation in abduction) and improvement of SPADI scores as patients were very much cooperative from the very beginning of treatment up to the end of follow up for consecutive six weeks and they were motivated well. Above all in this current study revealed patients compliance were good hence no patient was dropped out from the study in any group.

In the current study revealed that early physical therapy alleviates pain and facilitates restoration of functions among patients with adhesive capsulitis which were also found by Hamer $\mathrm{J}_{\text {etal }}{ }^{30}$, Maricar $\mathrm{N}$ etal ${ }^{32}$, Khan $\mathrm{AA}^{33}$ and Bal A etal ${ }^{34}$ in their studies.

\section{RECOMMENDATION}

- Study with longer duration should be carried out with large number of subjects.

- Multi centered study should be carried out to see the outcome of phonophoresis for the management of adhesive capsulitis.

- Compare with other deep and superficial heat modalities in adhesive capsulitis.

To see the ADL improvement before and after phonophoresis.

\section{CONCLUSION}

The current study was revealed exercise with or without phonophoresis has beneficial effects on adhesive capsulitis and phonophoresis has an additive effect on exercise to alleviate pain and for restoration of movements and activities of shoulders. Early implementations of these modalities of treatment are necessary to ameliorate the symptoms of adhesive capsulitis and eventually prevent permanent deformity and better outcome. Such physiotherapeutic approaches reduces patient's cost and probable side effects of analgesics and other medicines.

\section{DISCLOSURE}

All the authors declared no competing interest. 


\section{REFERENCES}

1. Martin SD, ThornhillnTS. Shoulder pain. In: Firestein GS, Budd RC, Harris ED etal. Kelley's Textbook of Rheumatology. $8^{\text {th }}$ ed. Elsevier: Saunders; 2009; 607-608.

2. Doherty M, Ralston SH. Musculoskeletal disease. In: Colledge NR, Walker BR, Ralston SH (editors). Davidson's principles \& practice of Medicine. $21^{\text {st }}$ edition. Elsevier: Churchill Livingstone; 2010;1069.

3. Fam AG. The Shoulder. In: Fam AG, Lawry GV, Kreder HJ. Musculoskeletal examination and joint injection Techniques. $1^{\text {st }}$ ed. Elsevier: Mosby; 2006; 21-22.

4. Cole A, Pavlou P. The shoulder and pectoral girdle.In.Solomon L, Warwick DJ, Nayagam S. Apley's System of Orthopaedics and Fractures. $9^{\text {th }}$ ed. Hodder Arnold; 2010; 351-353.

5. Arslan S, Celiker R. Comparison of the efficacy of local corticosteroid injection and physical therapy for the treatment of adhesive capsulitis. Rheumatol Int. 2001; 21(1): 20-23.

6. Zuckerman JD, Rokito A. Frozen shoulder: A consensus definition. J Shoulder Elbow Surg. 2010 Nov 2.

7. Kelly MJ, McClure PW, Leggin BG. Frozen shoulder: evidence and a proposed model guiding rehabilitation. J Orthop Sports Phys Ther. 2009; 39 (2): 135- 148.

8. Siegel LB, Cohen NJ, Gall EP. Adhesive Capsulitis: A Sticky Issue. Am Fam Physician. 1999; 59 (7): 1843-1850.

9. Langford CA, Gilliland BC. Periarticular Disorders of the Extremities. In: Fauci AS, Longo DL, Kasper DL, et al (editors). Harrison's Principles of Internal Medicine. $18^{\text {th }}$ ed. Mc Graw Hill; 2012; 2861-2862.

10. Tighe CB, Oakley WS. The prevalence of a diabetic condition and adhesive capsulitis of the shoulder. Southern Medical Journal. 2008; 101 (6): 591- 595

11. YAMSHON LJ. Frozen shoulder: methods for bringing about early mobilization. Calif Med. 1958; 89 (5): 333- 334.

12. Schultheis A, Reichwein F, Nebelung W. Frozenshoulder. Diagnosis and therapy. Orthopade. 2008; 37 (11): 1065- 1072.

13. Hanchard NC, Goodchild L, Thompson J, O'Brien T, Davison D, Richardson C. A questionnaire survey of UK physiotherapists on the diagnosis and management of contracted (frozen) shoulder. Physiotherapy. 2011; 97 (2): 115- 1125.

14. Brox JI, Sunde P, Schroder CP, Engebresten K, Skare O, Ekeberg OM, etal. Non-traumatic shoulder pain. Tidsskr Nor Laegeforen. 2010; 130 (21): 2132- 2135.

15. Ewald A. Adhesive capsulitis: a review. Am Fam Physician. 2011 Feb 15; 83 (4): 417-422.

16. Strang MH. Physiotherapy of the shoulder complex. Baillieres Clin Rheumatol. 198; 3 (3):669-680.

17. Justus F, Lehmann and Barbara J, Lateur D. The Clinical Use of Heat and Cold in various Conditions. In: kottke FJ, Lehmann JF (editors). KRUSEN'S HANDBOOK OF PHYSICAL MEDICINE and REHABILITATION. $4^{\text {th }}$ ed. Philadelphia: W.B.SAUNDERS; 1990; 285- 352.

18. Basford JR. Therapeutic Physical Agents. In: Delisa JA, Gans BM (editors). Physical Medicine \& Rehabilitation principles and practice. $4^{\text {th }}$ ed. Lippincott: Williams \& Wilkins; 2005; 257.

19. David C, Weber and Kurtis M, Hoppe. Physical Agent Modalities. In: Braddom RL (editor). Physical Medicine \& Rehabilitation. $3^{\text {rd }}$ ed. Elsevier: Saunders; 2007; 464- 472.

20. McRae R. Clinical Orthopaedic Examination. $6^{\text {th }}$ ed. Elsevier: Churchill Livingstone; 2010; $52-57$.

21. D’Cruz D. Locomotor system. In: Swash M, Glynn M (editor).Hutchison's Clinical Methods An integrated approach to clinical practice. $22^{\text {nd }}$ ed. Elsevier: Saunders; 2007; 155.

22. http:// www.tac.vic.gov.au/upload/SPI.pdf (retrieved on 15/1/2011)

23. Bhuiyan ZH. A study on patients with painful shoulders attending the Physical Medicine \& Rehabilitation department of RMCH, Rajshahi [FCPS dissertation]. Bangladesh College of Physicians \& Surgeons; 2008.

24. Khan AA. A study of patients with painful shoulders attending the Physical Medicine department of IPGMR, Dhaka [FCPS dissertation]. Bangladesh College of Physicians \& Surgeons; 1993.

25. Rahman MH, Moyeenuzzaman M, Samad MA, Islam H, Salek AKM, Islam MQ. Conservative Treatment of Adhesive Capsulitis: A Comparative Study. J INST POSTGRAD MED RES. 1997; 12 (1): 10-12.

26. Celik D. Comparison of the outcomes of two different exercise programs on frozen shoulder. Acta Orthop Traumatol Turc. 2010; 44 (4): 285-292.

27. Jurgel J, Rannama L, Gapeyeva H, Ereline J, Kolts I, Pasuke M. Shoulder function in patients with frozen shoulder before and after 4-week rehabilitation. Medicina (Kaunas). 2005; 41 (1): 30-38.

28. Dogru H, Basaran S, Sarpel T. Effectiveness of therapeutic ultrasound in adhesive capsulitis. Joint Bone Spine. 2008; 75: 445-450.

29. Lisinski P, Grabarczyk G. Aspects of physiotherapy in treatment of shoulder joint pain. Chir Narzadow Rucho Orthop Pol. 2005; 70 (4): 295-299.

30. Hamer J, Kirk JA. Physiotherapy and the frozen shoulder: a comparative trial of ice and ultrasonic therapy. N Z Med J. 1976; 83 (560): 191-192.

31. Green S, Buchbinder R, Hetrick S. Physiotherapy interventions for shoulder pain. Cochrane Database Syst Rev. 2003; (2): CD004258.

32. Maricar N, Shacklady C, McLoughlin L. Effect of Maitland mobilization and exercises for the treatment of shoulder adhesive capsulitis: a single-case design. Physiother Theory Pract. 200925 (3): 203-217.

33. Khan A A. Frozen shoulder: modalities of treatment. Bangladesh Medical Journal. 1998; 27 (3 \& 4): 63-65.

34. Bal A, Eksioglu E, Gulec B, Aydog E, Gurcay E, Cakci A. Effectiveness of corticosteroid injection in adhesive capsulitis. Clin Rehabil. 2008; 22 (6): 503-512. 